\title{
Clinical outcomes with besifloxacin ophthalmic suspension $0.6 \%$ in the treatment of bacterial conjunctivitis due to potentially consequential pathogens
}

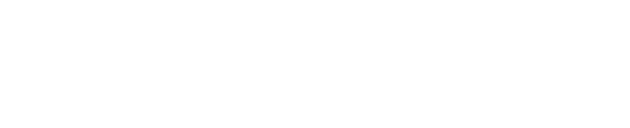

Timothy L Comstock'

Timothy W Morris ${ }^{2}$

Lynne S Gearinger ${ }^{2}$

Heleen H DeCory'

'Medical Affairs, ${ }^{2}$ Department of Microbiology and Sterilization Sciences, Bausch + Lomb, Rochester, NY, USA
Correspondence: Timothy L Comstock Medical Affairs, Bausch + Lomb, I 400 N Goodman St, Rochester, NY 14609, USA

Tel +| 585338 663 I; + | 585978 |938

Fax +I 5853380273

Email tcomstock@bausch.com
Purpose: Besifloxacin is a chlorofluoroquinolone approved for use in the treatment of bacterial conjunctivitis. This study assessed the clinical efficacy of besifloxacin ophthalmic suspension $0.6 \%$ against conjunctivitis infections caused by potentially consequential pathogens.

Design: Post hoc analysis of clinical outcomes for patients with conjunctival infections due to Pseudomonas aeruginosa, Serratia marcescens, Neisseria spp., methicillin-resistant Staphylococcus aureus (MRSA), and methicillin-resistant Staphylococcus epidermidis (MRSE) who were treated with besifloxacin in four multicenter, double-masked, randomized clinical trials.

Methods: Minimum inhibitory concentrations (MICs) of besifloxacin against potentially consequential pathogens were pooled. Clinical outcome data for patients treated with besifloxacin with baseline infections due to these pathogens were pooled and summarized. Bacterial eradication was defined as the absence of ocular bacterial species present at or above threshold at baseline.

Results: A total of 1,317 patients had culture-confirmed bacterial conjunctivitis across the four studies, and 151 infections were due to the aforementioned pathogens ( . aeruginos $\mathrm{n}=9$; S. marcescens $\mathrm{n}=10$; Neisseria spp. $\mathrm{n}=16$; MRSA $\mathrm{n}=35$; MRSE $\mathrm{n}=81$ ). Among MRSA and MRSE infections, 48.3\% demonstrated concurrent ciprofloxacin resistance (ciprofloxacinresistant [CipR]-MRSA n=24; CipR-MRSE n=32). The $\mathrm{MIC}_{90}$ (MIC for $90 \%$ of isolates) for besifloxacin was $1 \mu \mathrm{g} / \mathrm{mL}$ for $S$. marcescens, $0.25 \mu \mathrm{g} / \mathrm{mL}$ for Neisseria spp., $0.06 \mu \mathrm{g} / \mathrm{mL}$ for both ciprofloxacin-sensitive MRSA and ciprofloxacin-sensitive MRSE, and $4 \mu \mathrm{g} / \mathrm{mL}$ for both CipR-MRSA and CipR-MRSE. Against $P$. aeruginosa, the MIC range was $1-4 \mu \mathrm{g} / \mathrm{mL}$. Bacterial eradication rates in patients treated with besifloxacin were $100 \%$ by the first follow-up visit for infections due to P. aeruginosa, S. marcescens, and Neisseria spp. and $87.8 \%$ by the second follow-up visit for infections due to MRSA and MRSE.

Conclusion: The use of besifloxacin ophthalmic suspension $0.6 \%$ in the treatment of conjunctival infections due to potentially consequential pathogens resulted in high rates of bacterial eradication.

Keywords: Besivance, Pseudomonas aeruginosa, Serratia marcescens, Neisseria spp., MRSA, MRSE

\section{Introduction}

Bacterial conjunctivitis is a common eye infection characterized by mucopurulent discharge, redness, and crusty or adherent eyelids. ${ }^{1-4}$ While Haemophilus influenzae, Streptococcus pneumoniae, and Staphylococcus spp. are the most common etiological agents, Neisseria spp., Moraxella spp., viridans streptococci groups, Escherichia coli, Serratia marcescens, Proteus mirabilis, and Pseudomonas aeruginosa have also 
been identified as causative, albeit less frequently. ${ }^{5-9}$ Bacterial conjunctivitis usually resolves spontaneously in the majority of patients; however, treatment with broad-spectrum topical antibiotics is recommended to speed the time to recovery, reduce rates of relapse or contagion, and lower the risk of complications. ${ }^{1,7}$

Conjunctival infections caused by $P$. aeruginosa, $S$. marcescens, and Neisseria spp., all Gram-negative bacteria, are of concern to eye care practitioners due to their severity and potential for sequelae, if not successfully treated.,10-15 $P$. aeruginosa is an opportunistic pathogen and a well-known risk factor for bacterial keratitis; as many as one-third of cases associated with contact lens wear are attributed to P. aeruginosa. ${ }^{16-18}$ S. marcescens, like $P$. aeruginosa, is another ubiquitous opportunistic pathogen associated with contact lens-associated keratitis as well as some cases of endophthalmitis. ${ }^{13,14,19}$ Conjunctival infection with Neisseria gonorrhoeae, generally hyperacute, can progress into keratoconjunctivitis due to the bacterium's ability to penetrate intact corneal epithelium and is associated with a risk of corneal perforation. ${ }^{5,20,21}$ Epidemics of gonococcal keratoconjunctivitis in adults have been reported. ${ }^{22}$ Neisseria meningitidis conjunctival infections are similar in presentation to gonococcal infections; while corneal sequelae tend to be milder, $N$. meningitidis infections have been linked to a significant risk for meningeal or systemic infection. ${ }^{5,12}$

Of more recent and growing concern to eye care practitioners are conjunctival infections due to methicillin-resistant staphylococci. ${ }^{10} \mathrm{~A}$ recent report by the Centers for Disease Control and Prevention categorized methicillin-resistant Staphylococcus aureus (MRSA) among microorganisms presenting a serious threat to the US population and warned of its increased expansion beyond the health care setting into the general population. ${ }^{23}$ Indeed, several studies have documented an increased prevalence of methicillin-resistant staphylococci, both MRSA and methicillin-resistant Staphylococcus epidermidis (MRSE) in ocular infections in general, ${ }^{9,24-27}$ as well as in conjunctival infections specifically. ${ }^{28,29}$ Both Adebayo et al and Cavuoto et al reported an increase of at least 30\% in the prevalence of methicillin resistance among $S$. aureus isolates in their respective studies of conjunctival cultures evaluated over a 10-year period. ${ }^{28,29}$ Many of these methicillin-resistant strains showed concurrent resistance to other non- $\beta$-lactam antibiotics, including aminoglycosides, macrolides, tetracyclines, and/or fluoroquinolones, making the treatment of ocular infections caused by these pathogens a challenge. ${ }^{24-33}$ Although conjunctivitis infections with methicillin-resistant staphylococci are generally not vision-threatening, ${ }^{24}$ potentially catastrophic complications have been reported with other ocular infections involving such organisms (eg, keratitis, cellulitis, endophthalmitis). ${ }^{34-36}$

Topical fluoroquinolones are often used in the treatment of bacterial conjunctivitis due to their low toxicity, broad spectrum of activity, and bactericidal activity. ${ }^{37,38}$ While their efficacy against the common pathogens of bacterial conjunctivitis is well established, their clinical efficacy against infection due to the above Gram-negative pathogens or due to methicillin-resistant staphylococci is not as clear..$^{37,38}$ Besifloxacin (Figure 1) is a relatively new fluoroquinolone, specifically a chlorofluoroquinolone, introduced in 2009. ${ }^{39}$ Cambau et al showed that besifloxacin has potent and balanced dual-targeting activity against both DNA gyrase and topoisomerase IV. ${ }^{40}$ This balanced activity, in turn, results in broad-spectrum in vitro activity, including activity against P. aeruginosa, S. marcescens, and Neisseria spp., as well as ciprofloxacin-resistant (CipR) and methicillin-resistant staphylococcal isolates. ${ }^{6,31,32,41,42}$ The ophthalmic formulation of besifloxacin, which contains $0.663 \%$ besifloxacin hydrochloride or $0.6 \%$ besifloxacin free base (Besivance ${ }^{\circledR}$; Bausch + Lomb, Bridgewater, NJ, USA $)^{39}$ is formulated with DuraSite ${ }^{\circledR}$ (InSite Vision, Alameda, CA, USA), a mucoadhesive polycarbophil polymer designed to prolong a drug's residence time on the ocular surface and improve bioavailability. ${ }^{43-46}$ DuraSite has also been reported to inhibit staphylococcal biofilm formation in vitro. ${ }^{47}$ The ophthalmic formulation of besifloxacin is currently approved for the treatment of bacterial conjunctivitis in the US, Canada, and several Latin American and Asian countries.

The objective of this post hoc analysis was to assess the clinical efficacy of besifloxacin ophthalmic suspension $0.6 \%$ against ocular infections caused by $P$. aeruginosa, $S$. marcescens, Neisseria spp., and methicillin-resistant staphylococci from four clinical studies of besifloxacin in the

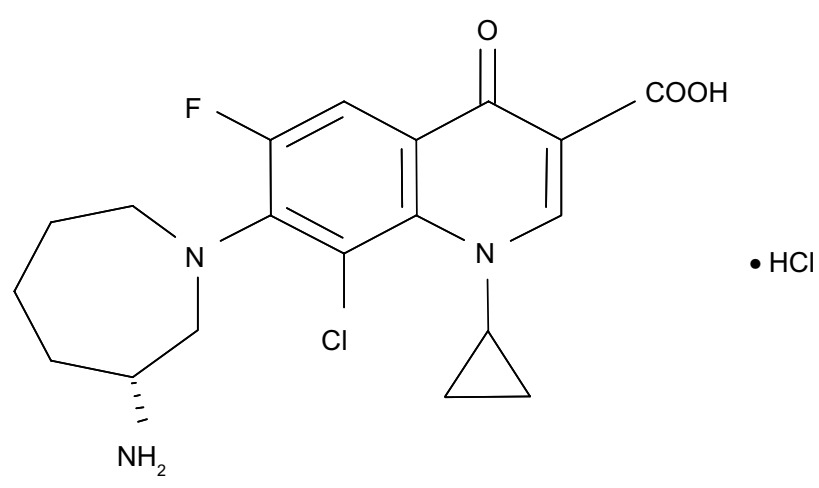

Figure I Molecular structure of besifloxacin hydrochloride. 
treatment of bacterial conjunctivitis. Because conjunctival infections due to these bacterial pathogens are uncommon, clinical outcomes for patients with these infections were pooled across the four studies for analysis. Case summaries for individual patients with $P$. aeruginosa conjunctival infections across these studies were described previously, ${ }^{48}$ and pooled outcomes for these patients are repeated here.

\section{Methods}

\section{Study design}

This study evaluated cases of conjunctivitis caused by P. aeruginosa, S. marcescens, Neisseria spp., MRSA, and MRSE from four prospective, randomized, multicenter, double-masked clinical studies of besifloxacin ophthalmic suspension $0.6 \%$, including three vehicle-controlled studies $\left(\mathrm{NCT} 00622908,{ }^{49} \mathrm{NCT} 00347932,{ }^{50} \text { and NCT00972777) }\right)^{51}$ and one active-comparator study (NCT00348348). ${ }^{52}$ All trial protocols were conducted in accordance with Good Clinical Practice, the International Conference on Harmonization guidelines, the Declaration of Helsinki, and the Health Insurance Portability and Accountability guidelines. Individual study results have been published previously. ${ }^{53-56}$ The active comparator study ${ }^{55}$ and two of the vehicle-controlled studies ${ }^{53,54}$ employed a 5-day thrice-daily treatment regimen, while the third vehicle-controlled study ${ }^{56}$ employed a 3-day twice-daily treatment regimen (Table 1).

Detailed subject inclusion and exclusion criteria and study procedures were described previously. ${ }^{53-56}$ Briefly, eligible patients were aged $\geq 1$ year with a diagnosis of bacterial conjunctivitis, as evidenced by a severity for both purulent ocular discharge and bulbar conjunctival injection of grade 1 or higher on a 4 -point scale $(0=$ absent, $1=$ mild,
$2=$ moderate, and $3=$ severe $)$ in at least one eye, and had a pinhole visual acuity (VA) of 20/200 or better in both eyes. The severity of bulbar conjunctival injection was determined using photographic standards (Ora Calibra ${ }^{\mathrm{TM}}$ Bacterial Conjunctivitis Bulbar Conjunctiva Redness Scale; Ora Inc., North Andover, MA, USA) employed in previous conjunctivitis research. ${ }^{8}$ Patients were excluded if they had used any topical ophthalmic products within 48 hours of enrollment or systemic or topical antimicrobial medication within 72 hours of enrollment or had suspected viral or allergic conjunctivitis, iritis, corneal erosion, or keratitis. Eligible patients completed three study visits. At the first visit (day 1 or baseline), patients underwent an eye examination that included pinhole VA, biomicroscopy, and ophthalmoscopy in both eyes. Samples for microbial cultures were taken from the conjunctival cul-de-sac of the affected eye(s), and patients were randomized to study treatment. Patients were instructed to administer one drop of study medication in the affected eye(s) three times daily at approximately 6-hour intervals for 5 days, ${ }^{53-55}$ or twice daily at approximately 8-hour intervals during waking hours for a total of 3 days.$^{56}$ Patients returned to the study site at or near the end of treatment (visit 2, day $5[ \pm 1]^{53,55}$ or day 4 or $\left.5^{54,56}\right)$ and after treatment ended on days 7 through 9 (visit 3 , day 8 or $9^{53-55}$ or day $7[ \pm 1]^{56}$ ) for clinical assessment of ocular signs and symptoms, VA testing, biomicroscopy, ophthalmoscopy (visit 3 only), and culture of infected eye(s). Ocular and non-ocular adverse events (AEs) were recorded at each visit.

In all four studies, the same central laboratory (Covance Central Laboratory Services, Indianapolis, IN, USA) identified and enumerated bacterial pathogens and/or viral pathogens in cultures from affected eye(s). For bacterial

Table I Multicenter, randomized, double-masked, controlled studies of besifloxacin ophthalmic suspension $0.6 \%$ in the treatment of bacterial conjunctivitis

\begin{tabular}{|c|c|c|c|c|}
\hline & Karpecki et al ${ }^{54}$ & Tepedino et $\mathbf{a l}^{53}$ & McDonald et $\mathrm{al}^{55}$ & DeLeon et $\mathrm{al}^{56}$ \\
\hline Comparator & Vehicle & Vehicle & $\begin{array}{l}\text { Moxifloxacin ophthalmic } \\
\text { solution, } 0.5 \%\end{array}$ & Vehicle \\
\hline Number of patients & 269 & 957 & $I, 161$ & 474 \\
\hline Dosing regimen & Thrice daily, 5 days & Thrice daily, 5 days & Thrice daily, 5 days & Twice daily, 3 days \\
\hline \multirow[t]{2}{*}{$\begin{array}{l}\text { Patients with clinical } \\
\text { resolution }\end{array}$} & $\begin{array}{l}\text { Visit } 2: 33.3 \% \text { vs } 17.2 \% \\
(P=0.069)\end{array}$ & $\begin{array}{l}\text { Visit } 2:^{\mathrm{a}} 45.2 \% \text { vs } 33.0 \% \\
(P=0.0084)\end{array}$ & $\begin{array}{l}\text { Visit } 2: a \mathrm{a} 8.3 \% \text { vs } 59.4 \% \\
(P=0.6520)\end{array}$ & $\begin{array}{l}\text { Visit } 2:{ }^{\mathrm{a}} 65.9 \% \text { vs } 44.0 \% \\
(P<0.00 \mathrm{I})\end{array}$ \\
\hline & $\begin{array}{l}\text { Visit 3: } 73.3 \% \text { vs } 43.1 \% \\
(P<0.001)\end{array}$ & $\begin{array}{l}\text { Visit 3: } 84.4 \% \text { vs } 69.1 \% \\
(P=0.001 \mathrm{I})\end{array}$ & $\begin{array}{l}\text { Visit 3: } 84.5 \% \text { vs } 84.0 \% \text {, } \\
(P=0.50 \mid 4)\end{array}$ & $\begin{array}{l}\text { Visit } 3: 76.3 \% \text { vs } 66.7 \% \\
(P=0.209)\end{array}$ \\
\hline \multirow[t]{2}{*}{$\begin{array}{l}\text { Patients with bacterial } \\
\text { eradication }\end{array}$} & $\begin{array}{l}\text { Visit } 2: 90.0 \% \text { vs } 46.6 \% \\
(P<0.00 \mathrm{I})\end{array}$ & $\begin{array}{l}\text { Visit 2: }{ }^{\text {a }} 91.5 \% \text { vs } 59.7 \% \\
(P<0.000 \mathrm{I})\end{array}$ & $\begin{array}{l}\text { Visit 2: } 93.3 \% \text { vs } 91.1 \% \text {, } \\
(P=0.1238)\end{array}$ & $\begin{array}{l}\text { Visit 2:a } 85.2 \% \text { vs } 54.6 \% \\
(P<0.00 \mathrm{I})\end{array}$ \\
\hline & $\begin{array}{l}\text { Visit 3:a } 88.3 \% \text { vs } 60.3 \% \\
(P<0.00 \mathrm{I})\end{array}$ & $\begin{array}{l}\text { Visit 3: } 88.4 \% \text { vs } 71.7 \% \\
(P<0.000 \mathrm{I})\end{array}$ & $\begin{array}{l}\text { Visit } 3: 87.3 \% \text { vs } 84.7 \% \\
(P=0.0608)\end{array}$ & $\begin{array}{l}\text { Visit } 3: 85.2 \% \text { vs } 64.5 \% \\
(P<0.00 \mathrm{I})\end{array}$ \\
\hline
\end{tabular}

Notes: aPrimary outcome visit. Visit 2 occurred at or near the end of treatment on day $5[ \pm 1]^{53,55}$ or day 4 or $5,{ }^{54,56}$ while visit 3 occurred following cessation of treatment on day 8 or $9^{53-55}$ or day $7[ \pm 1] .^{56}$ 
pathogens, serial dilutions of test samples were plated onto bacteriological media, and the resulting colony-forming units (CFUs) were enumerated and speciated by standard biochemical and/or molecular identification methods. Patients were considered culture-positive if the count for a particular species (in CFUs $/ \mathrm{mL}$ ) equaled or exceeded threshold values on the Cagle list, as modified by Leibowitz. ${ }^{57,58}$ For the bacteria studied in this post hoc analysis, the threshold criterion was $1 \mathrm{CFU} / \mathrm{mL}$ for infections attributed to $P$. aeruginosa, S. marcescens, and Neisseria spp.; $10 \mathrm{CFUs/mL}$ for infections attributed to $S$. aureus; and $100 \mathrm{CFUs} / \mathrm{mL}$ for infections attributed to $S$. epidermidis. In vitro susceptibilities to besifloxacin and comparator antibacterial agents, also conducted by the same central laboratory, were determined for all isolates that met the threshold criteria. Antibacterial susceptibility testing was conducted by broth microdilution following the recommended procedures of the Clinical and Laboratory Standards Institute (CLSI). ${ }^{59-63}$ Comparator antibacterial agents evaluated included moxifloxacin, ciprofloxacin, gatifloxacin, levofloxacin, and azithromycin. S. aureus and S. epidermidis isolates were further designated as methicillin-sensitive or -resistant and as ciprofloxacinsensitive (CipS) or CipR, based on CLSI breakpoint criteria for oxacillin and ciprofloxacin. ${ }^{63}$

\section{Outcomes}

The primary efficacy endpoints in all studies included eradication of the baseline bacterial infection and resolution of the clinical signs of conjunctivitis in patients with cultureconfirmed bacterial conjunctivitis. Bacterial eradication was defined as the absence of ocular bacterial species that were present at or above the Cagle threshold at baseline (visit 1). ${ }^{57,58}$ Clinical resolution was defined as the absence (grade 0 ) of both ocular discharge and bulbar conjunctival injection. In each study, a single eye (study eye) from each randomized patient was represented in the analysis of the primary efficacy endpoints. In this post hoc analysis, either eye could contribute data provided an infecting bacterial species was at or above threshold and the eye had at least grade 1 conjunctival discharge and bulbar conjunctival injection at baseline. If a patient had a bilateral infection with the same relevant pathogen, only the eye with the most severe clinical signs was included.

Patients with conjunctival infections attributed to infection with $P$. aeruginosa, S. marcescens, Neisseria spp., MRSA, or MRSE were identified across the four clinical studies. Baseline minimum inhibitory concentrations (MICs) for besifloxacin and comparator antibacterial agents against the causative bacterial isolates from these patients were pooled and integrated, and $\mathrm{MIC}_{90}$ values (MIC for $90 \%$ of isolates) were generated for those pathogens with 10 or more isolates. Bacterial eradication and clinical resolution data for patients infected with the aforementioned pathogens at baseline and randomized to treatment with besifloxacin were also pooled, and integrated rates in the pooled sample were summarized by follow-up visit for those patients with non-missing data. Where noted, rates for clinical resolution and bacterial eradication were analyzed using Pearson's $\chi^{2}$ test.

\section{Results}

Of the 2,859 patients that were randomized and treated in the four studies, 1,317 patients had culture-confirmed bacterial conjunctivitis. Among these, there were 35 conjunctivitis infections attributed to the Gram-negative pathogens of interest: nine $P$. aeruginosa infections, ten $S$. marcescens infections, and 16 Neisseria spp. infections ( $N$. meningitidis $\mathrm{n}=3$; $N$. gonorrhoeae $\mathrm{n}=2 ;$ Neisseria sicca $\mathrm{n}=1$; Neisseria subflava $\mathrm{n}=8$; Neisseria mucosa $\mathrm{n}=2$ ). There were 256 infections with $S$. aureus and 178 infections with $S$. epidermidis. Figure 2 presents the proportion of staphylococcal infections due to strains resistant to methicillin and/or ciprofloxacin. A total of $116(8.8 \%)$ infections were due to methicillin-resistant staphylococci: 35 (2.7\%) MRSA infections and 81 (6.2\%) MRSE infections. Concurrent ciprofloxacin resistance was observed in $68.6 \%(24 / 35)$ of MRSA infections and $39.5 \%$ $(32 / 81)$ of MRSE infections.

Figure 3 presents the $\mathrm{MIC}_{90}$ for besifloxacin and comparator fluoroquinolones against $P$. aeruginosa, $S$. marcescens, and Neisseria spp. isolates pooled from all four studies. All fluoroquinolones demonstrated in vitro activity against these Gram-negative pathogens. Ciprofloxacin had the lowest MICs against $P$. aeruginosa and $S$. marcescens. However, besifloxacin had the same $\mathrm{MIC}_{90}$ as ciprofloxacin against Neisseria spp. Figure 4 presents the $\mathrm{MIC}_{90}$ for besifloxacin and comparator fluoroquinolones against MRSA and MRSE isolates from all four studies. The $\mathrm{MIC}_{90}$ of besifloxacin against MRSA isolates was $0.06 \mu \mathrm{g} / \mathrm{mL}$ for CipS-MRSA and CipS-MRSE, and $4 \mu \mathrm{g} / \mathrm{mL}$ for both CipR-MRSA and CipR-MRSE. Against CipR-MRSA and CipR-MRSE, the $\mathrm{MIC}_{90}$ for besifloxacin was eight- to 128 -fold lower and eight- to 64-fold lower, respectively, than comparator fluoroquinolones. Azithromycin, which was also included as a comparator in susceptibility testing, had poor activity against these staphylococcal isolates, with an $\mathrm{MIC}_{90}$ of either $>8 \mu \mathrm{g} / \mathrm{mL}$ or $\geq 256 \mu \mathrm{g} / \mathrm{mL}$ (dependent on the highest drug dilution tested) for CipS-MRSA, CipS-MRSE, CipR-MRSA and CipR-MRSE. 

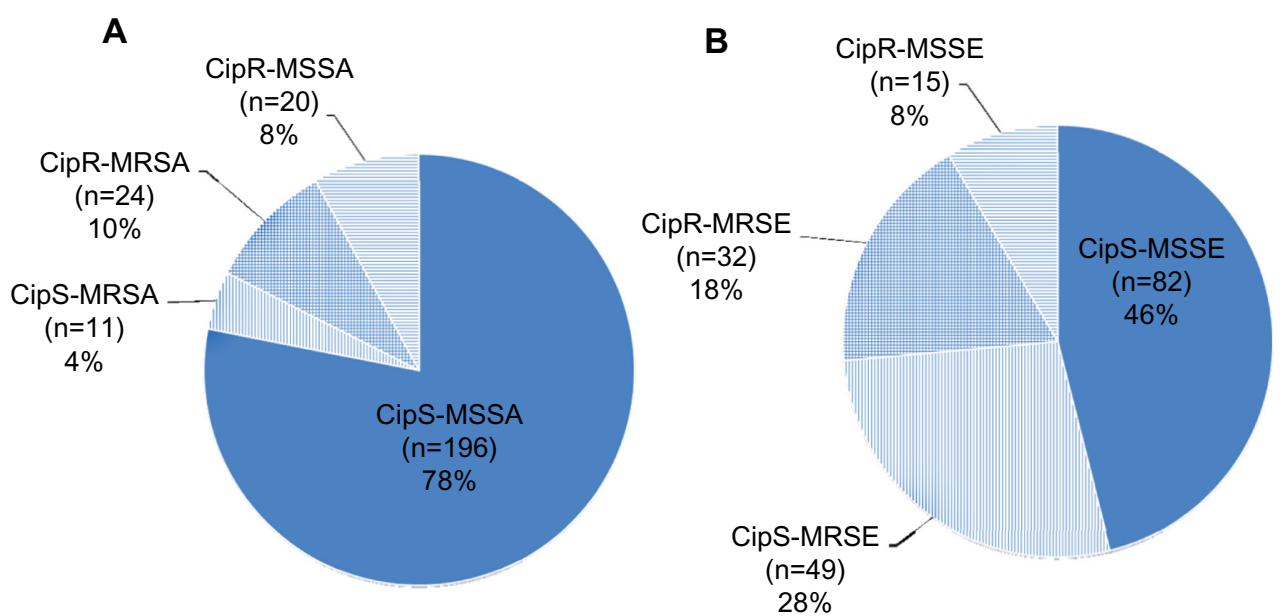

Figure 2 Drug resistance among staphylococcal isolates in four bacterial conjunctivitis trials.

Notes: (A) Staphylococcus aureus ( $\mathrm{n}=256$ ); (B) Staphylococcus epidermidis $(\mathrm{n}=178)$.

Abbreviations: CipS, ciprofloxacin-sensitive; CipR, ciprofloxacin-resistant; MRSA, methicillin-resistant Staphylococcus aureus; MRSE, methicillin-resistant Staphylococcus epidermidis; MSSA, methicillin-sensitive Staphylococcus aureus; MSSE, methicillin-sensitive Staphylococus epidermidis.

\section{Integrated clinical outcomes}

Fourteen patients with conjunctivitis infections due to Gramnegative pathogens of concern were randomized to treatment with besifloxacin ophthalmic suspension $0.6 \%$. Two of the 14 patients were infected with both P. aeruginosa and S. marcescens (ie, both pathogens were present above the Cagle threshold at baseline $)^{57,58}$ for a total of 16 conjunctival infections attributed to Gram-negative pathogens of consequence (P. aeruginosa $\mathrm{n}=5 ;$ S. marcescens $\mathrm{n}=4$; Neisseria spp. $\mathrm{n}=7$ [N. gonorrhoeae $\mathrm{n}=2, N$. meningitides $\mathrm{n}=2, N$. subflava $\mathrm{n}=2$ and $N$. sicca $\mathrm{n}=1]$ ). The 14 patients ranged in age from 1 to 81 years, and eight (57.1\%) patients were female. Half of the patients were infected with additional bacterial pathogens that were not the focus of this analysis. None of the patients
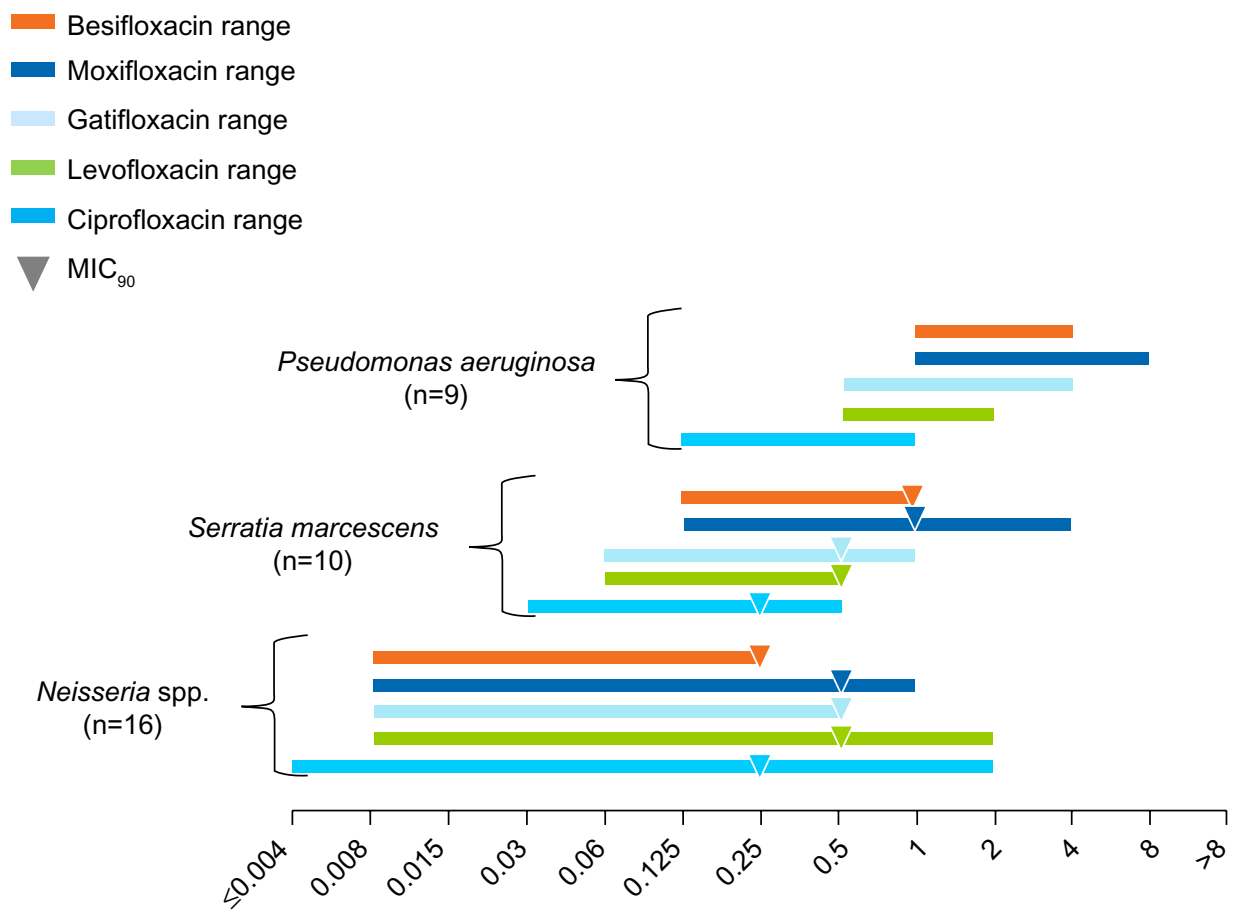

\section{MIC $(\mu \mathrm{g} / \mathrm{mL})$}

Figure 3 In vitro activity of besifloxacin and comparator fluoroquinolones against potentially consequential pathogens.

Notes: Due to the limited number of Pseudomonas aeruginosa isolates, a MIC $\mathrm{C}_{90}$ could not be calculated. The 16 Neisseria spp. isolates include Neisseria meningitidis ( $\mathrm{n}=3$ ), Neisseria gonorrhoeae $(n=2)$, Neisseria sicca $(n=1)$, Neisseria subflava $(n=8)$, and Neisseria mucosa $(n=2)$.

Abbreviations: MIC, minimum inhibitory concentration; $\mathrm{MIC}_{90}$, MIC for $90 \%$ of isolates. 

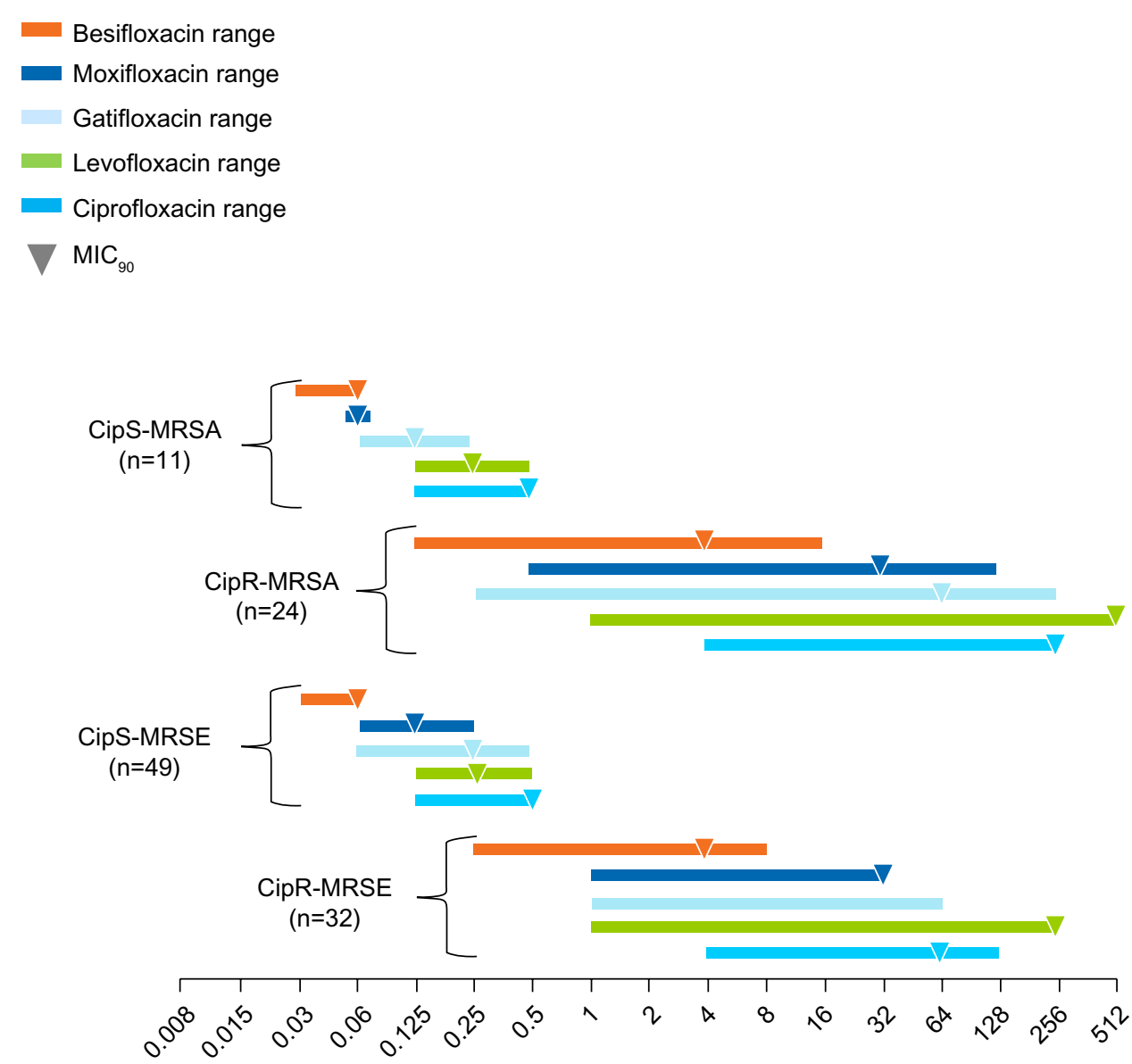

$\operatorname{MIC}(\mu \mathrm{g} / \mathrm{mL})$

Figure 4 In vitro activity of besifloxacin and comparator fluoroquinolones against methicillin-resistant staphylococci.

Abbreviations: CipS, ciprofloxacin-sensitive; CipR, ciprofloxacin-resistant; MIC, minimum inhibitory concentration; MIC ${ }_{90}$, MIC for $90 \%$ of isolates; MRSA, methicillinresistant Staphylococcus aureus; MRSE, methicillin-resistant Staphylococcus epidermidis.

had positive viral cultures. The MIC range of besifloxacin against isolates from this subset of patients was $1-4 \mu \mathrm{g} / \mathrm{mL}$ for $P$. aeruginosa, $0.125-0.5 \mu \mathrm{g} / \mathrm{mL}$ for $S$. marcescens, and $0.008-0.25 \mu \mathrm{g} / \mathrm{mL}$ for Neisseria spp. Figure 5 presents bacterial eradication and clinical resolution rates at the first follow-up visit (visit 2) and the second follow-up visit (visit 3) for these patients by infecting Gram-negative pathogen. Treatment with besifloxacin ophthalmic suspension led to bacterial eradication of the infecting pathogen by the first follow-up visit in $100 \%(16 / 16)$ of these patients. The proportion of patients with clinical resolution (absence of both ocular discharge and bulbar conjunctival injection) was $40 \%(2 / 5)$ for $P$. aeruginosa infections, $25 \%$ (1/4) for $S$. marcescens infections, and $57 \%$ (4/7) for Neisseria spp. infections at the first follow-up visit and increased to $80 \%(4 / 5), 75 \%(3 / 4)$, and $100 \%(7 / 7)$, respectively, at the second follow-up visit.

Forty-eight patients with infections due to methicillinresistant staphylococci were randomized to treatment with besifloxacin ophthalmic suspension $0.6 \%$. One of the 48 patients was infected with both MRSE and MRSA for a total of 12 MRSA infections and 37 MRSE infections, including ten CipR-MRSA infections and 16 CipR-MRSE infections. The 48 patients ranged in age from 1 to 87 years with a mean age of 40.8 (standard deviation 26.2) years, and 26 (54.2\%) were female. One patient with MRSA was coinfected with herpes simplex virus, and one patient with MRSE was coinfected with adenovirus. As was reported for the Gram-negative cases, multibacterial infections were also common in this group. The $\mathrm{MIC}_{90}$ of besifloxacin against these isolates was $2 \mu \mathrm{g} / \mathrm{mL}$ for CipR-MRSA, $0.06 \mu \mathrm{g} / \mathrm{mL}$ for CipS-MRSE, and $4 \mu \mathrm{g} / \mathrm{mL}$ for CipR-MRSE. The MIC values of besifloxacin against the two CipS-MRSA strains were 0.03 and $0.06 \mu \mathrm{g} / \mathrm{mL}$.

Bacterial eradication rates in patients treated with besifloxacin for infections due to either MRSA or MRSE were $81.2 \%(40 / 49)$ by the first follow-up visit (visit 2 ) and $87.8 \%$ 


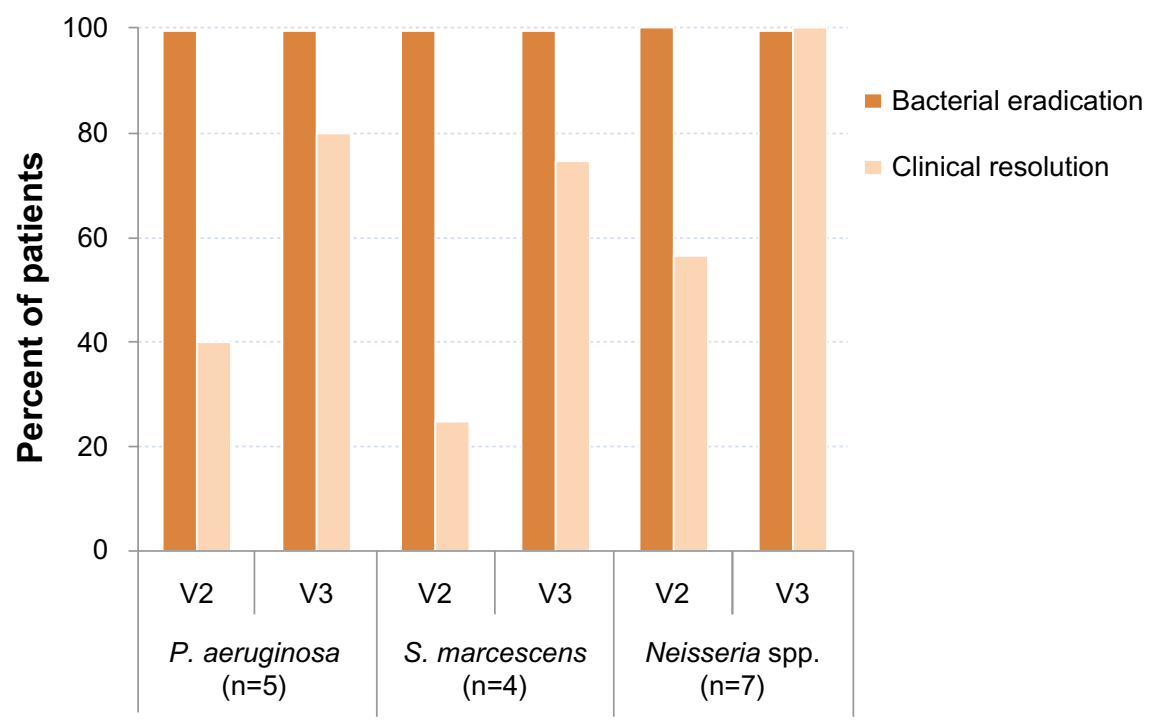

Figure 5 Bacterial eradication and clinical resolution at visit $(\mathrm{V}) 2$ and V3 for patients with Gram-negative pathogens of potential consequence at baseline treated with besifloxacin ophthalmic suspension $0.6 \%$.

Abbreviations: P. aeruginosa, Pseudomonas aeruginosa; S. marcescens, Serratia marcescens.

(43/49) by the second follow-up visit (visit 3). Clinical resolution rates were $49.0 \%(24 / 49)$ by the first follow-up visit and increased to $73.5 \%$ (36/49) by the second follow-up visit. Bacterial eradication rates were significantly higher than those obtained for these infections in patients treated with vehicle $(57.1 \%$ [20/35] by the first and $50.0 \%$ [17/34] by the second follow-up visit; $P \leq 0.014$ ). Clinical resolution rates did not differ statistically from those obtained for these infections in patients treated with vehicle $(51.4 \%$ [18/35] by the first and $67.6 \%$ [23/34] by the second follow-up visit; $P \geq 0.56$ ). Figure 6 presents bacterial eradication and clinical resolution rates at the first and second follow-up visits for these patients by ciprofloxacin sensitivity of the infecting MRSA or MRSE strain. The bacterial eradication rate at first follow-up visit was $100 \%$ (2/2) for CipS-MRSA infections, $70 \%$ (7/10) for CipR-MRSA infections, 71\% (15/21) for CipS-MRSE infections, and 100\% (16/16) for CipR-MRSE infections, and the rates increased to $80 \%(8 / 10)$ for CipRMRSA infections and 81\% (17/21) for CipS-MRSE infections by the second follow-up visit. The clinical resolution rate at the first follow-up visit was 50\% (1/2) for CipS-MRSA infections, $20 \%(2 / 10)$ for CipR-MRSA infections, $71 \%$ (15/21) for CipS-MRSE infections, and 37.5\% (6/16) for CipR-MRSE infections, and 50\% (1/2), 50\% (5/10), 85.7\%

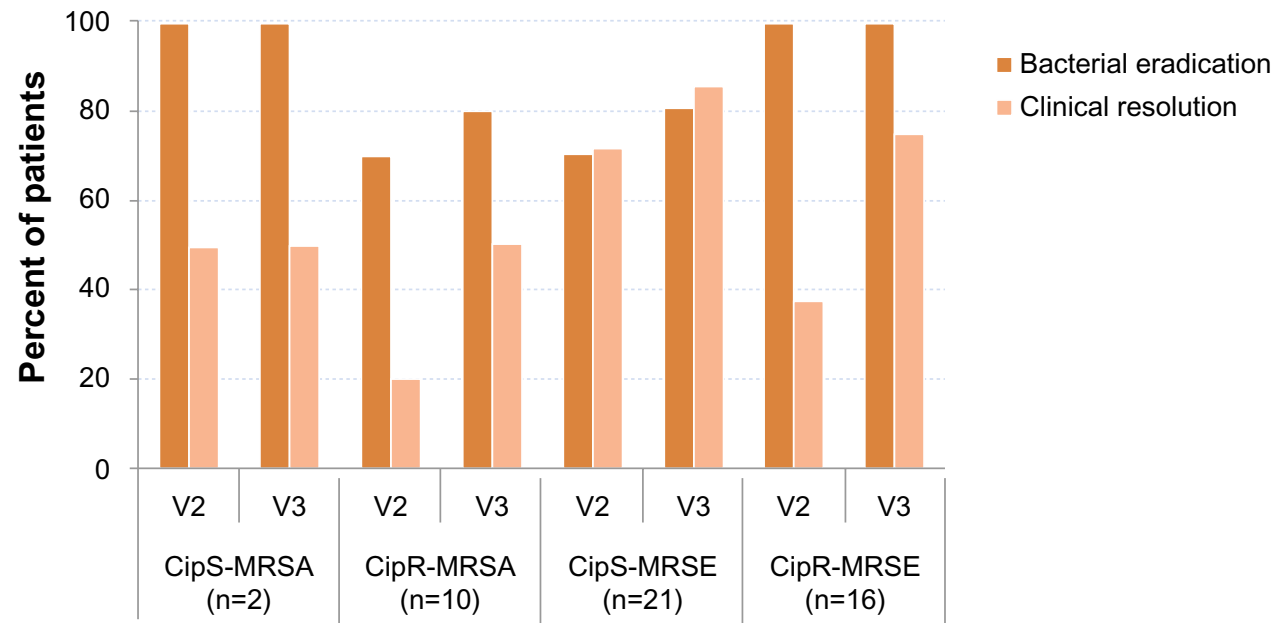

Figure 6 Bacterial eradication and clinical resolution at visit $(\mathrm{V}) 2$ and $\mathrm{V} 3$ for patients with methicillin-resistant staphylococcal infections at baseline treated with besifloxacin ophthalmic suspension $0.6 \%$.

Abbreviations: CipS, ciprofloxacin-sensitive; CipR, ciprofloxacin-resistant; MRSA, methicillin-resistant Staphylococcus aureus; MRSE, methicillin-resistant Staphylococcus epidermidis. 
$(18 / 21)$, and $75 \%(12 / 16)$, for the respective infections, at the second follow-up visit.

\section{Discussion}

Previous multicenter, randomized, double-masked, controlled clinical studies have established the safety and efficacy of besifloxacin ophthalmic suspension $0.6 \%$ for the treatment of bacterial conjunctivitis, whether administered thrice daily for 5 days ${ }^{53-55}$ or twice daily for 3 days. ${ }^{56}$ In each of these studies, clinical efficacy was demonstrated for patients with culture-confirmed bacterial conjunctivitis when pooling infections by all causative pathogens (Table 1) and also in the following subsets: infections due to Gram-positive pathogens; infections due to Gram-negative infections; and infections due to $H$. influenzae, S. pneumoniae, S. aureus, or S. epidermidis, the most prevalent bacterial pathogens in these studies. Based on data from thrice-daily studies, besifloxacin ophthalmic suspension $0.6 \%$ was initially approved in 2009 for treatment of bacterial conjunctivitis due to these species as well as some less frequent causative species encountered in these studies, including CDC coryneform group G, Corynebacterium pseudodiphtheriticum, Corynebacterium striatum, Moraxella lacunata, Staphylococcus hominis, Staphylococcus lugdunensis, Streptococcus mitis group, Streptococcus oralis, and Streptococcus salivarius. ${ }^{64}$

Besifloxacin has been reported to have a broad-spectrum activity with an $\mathrm{MIC}_{90}$ against $P$. aeruginosa, $S$. marcescens, Neisseria spp., and methicillin-resistant staphylococci that is significantly lower than the mean concentration of besifloxacin in tears following a single topical instillation in human volunteers (from $610 \mu \mathrm{g} / \mathrm{g}$ at 10 minutes to $>10 \mu \mathrm{g} / \mathrm{g}$ at 12 hours following administration). ${ }^{65}$ These data suggest that besifloxacin could be clinically effective against these potentially consequential pathogens, although there were too few infections with these pathogens in any individual clinical study to confirm this. Furthermore, the efficacy of besifloxacin has been reported in cases of $P$. aeruginosa keratitis ${ }^{66}$ and giant fornix syndrome. ${ }^{67}$ Besifloxacin was also effective in decreasing the bacterial counts in rabbit models of keratitis due to $P$. aeruginosa ${ }^{68}$ and MRSA. ${ }^{69,70}$

The objective of this post hoc analysis was to assess the clinical efficacy of besifloxacin ophthalmic suspension $0.6 \%$ when used in the treatment of patients with conjunctivitis caused by the aforementioned group of potentially consequential bacterial pathogens across four clinical studies. ${ }^{53-56}$ Case summaries for individual patients with $P$. aeruginosa conjunctival infections have been published previously, ${ }^{48}$ and pooled outcomes for these patients repeated here. As expected, the number of infections due to $P$. aeruginosa, $S$. marcescens, and Neisseria spp. was low even in the pooled data set. Nevertheless, there was a sufficient number of infections to demonstrate that besifloxacin had good in vitro activity against isolates of these Gram-negative pathogens comparable to that of ciprofloxacin against Neisseria spp. Analysis of integrated clinical outcome data for infections with these pathogens in patients treated with besifloxacin ophthalmic suspension demonstrated eradication of the infecting bacterial pathogen in all patients as early as the first follow-up visit. Indeed, the integrated bacterial eradication and clinical resolution data for P. aeruginosa formed the basis of a revision in 2012 of the US Food and Drug Administration-approved labeling for besifloxacin ophthalmic suspension $0.6 \%$ to include $P$. aeruginosa to its list of indicated bacterial pathogens (three additional pathogens - Aerococcus viridans, Moraxella catarrhalis, and Staphylococcus warneri - were also included at that time). ${ }^{39}$ Because the approval to include a particular bacterial species in the label of an antibiotic is dependent on data being available for a minimum of five patients/infections successfully treated with that antibiotic, the addition of $S$. marcescens or any individual Neisseria spp. to the label for besifloxacin ophthalmic suspension $0.6 \%$ was not a consideration.

Consistent with reports on the increased prevalence of methicillin resistance among staphylococci in ocular infections, ${ }^{24-29}$ a larger data set, albeit still small, was available for analysis of clinical outcomes in conjunctivitis patients infected with methicillin-resistant staphylococci. Of $S$. aureus and $S$. epidermidis infections across the four clinical studies, $14 \%$ and $46 \%$, respectively, were methicillin-resistant strains (Figure 2). In addition, a high proportion of methicillinresistant strains were also resistant to ciprofloxacin $(69 \%$ of MRSA strains and 40\% of MRSE strains). In comparison, ciprofloxacin resistance was observed in a much smaller proportion of methicillin-sensitive $S$. aureus and $S$. epidermidis strains ( $9 \%$ and $15 \%$, respectively). In agreement with previous studies, ${ }^{6,31,32,41}$ besifloxacin demonstrated potent in vitro activity against methicillin-resistant staphylococcal isolates, with $\mathrm{MIC}_{90}$ values against CipR-MRSA and CipR-MRSE at least eight- to 128-fold lower than that of other fluoroquinolones and comparable to that reported for vancomycin in recent surveillance studies $(1-2 \mu \mathrm{g} / \mathrm{mL}) .{ }^{31,41}$ Miller et al evaluated the comparative efficacy of besifloxacin against MRSA and coagulase-negative staphylococci from a wide variety of ocular infections (eg, conjunctivitis, blepharitis, keratitis, endophthalmitis, and other ocular surface disorders) and likewise showed lower $\mathrm{MIC}_{90}$ values with besifloxacin compared to other fluoroquinolones and other antibacterials, 
in particular against those staphylococcal isolates that were both CipR and methicillin resistant. ${ }^{42}$ Similar to results obtained with the Gram-negative pathogens of concern, bacterial eradication rates in patients with MRSA and MRSE infections treated with besifloxacin ophthalmic suspension were high $-81.2 \%$ by the first follow-up visit, increasing to $87.8 \%$ by the second follow-up visit - and significantly higher than those obtained in patients with these infections treated with vehicle $(P \leq 0.014)$. Eradication rates were also high in the subset of infections with CipR-MRSA or CipR-MRSE $-88.5 \%$ at first follow-up visit, increasing to $92.3 \%$ by the second follow-up visit - suggesting that the combination of low $\mathrm{MIC}_{90}$ and sustained ocular surface drug concentrations provides excellent coverage for these multidrug-resistant infections.

For both infections caused by the Gram-negative pathogens of concern, as well as infections caused by methicillinresistant staphylococci, rates for clinical resolution (defined as the complete absence of both ocular discharge and conjunctival injection) were not as robust as rates for bacterial eradication. Indeed, there was no significant difference in clinical resolution rates in patients with MRSA and MRSE infections treated with besifloxacin compared to those treated with vehicle. These results were not unexpected based on the small sample size, with previous studies reporting a delay in clinical resolution relative to bacterial eradication, ${ }^{7,71,72}$ and strict criteria used in defining clinical resolution - namely, the complete absence (grade 0 ) of both ocular discharge and bulbar conjunctival injection. Notably, further evaluation of clinical signs in those patients for whom complete clinical resolution was not reported demonstrated that the severity of these clinical signs was reduced in all cases. ${ }^{73,74}$

Although not a focus of this post hoc analysis, treatment with besifloxacin ophthalmic suspension $0.6 \%$ did not present any safety concerns in patients with infections due to pathogens of potential consequence. There were only two ocular AE reports considered to be at least possibly drug related: post-instillation blurred vision in one patient and mild corneal staining that was resolved at the follow-up visit in another patient. There were no clinically meaningful biomicroscopy findings or fundus pathologies observed, and final VA was the same or improved relative to baseline in nearly all patients. These findings are consistent with the overall safety findings from the individual studies.

\section{Conclusion}

Results of this post hoc analysis showed that treatment of patients with conjunctival infections due to P. aeruginosa,
S. marcescens, Neisseria spp., or methicillin-resistant staphylococci with besifloxacin ophthalmic suspension $0.6 \%$ led to high rates of bacterial eradication of these pathogens of concern to eye care practitioners. Furthermore, besifloxacin was well tolerated, with no clinically meaningful AEs or ophthalmoscopy/biomicroscopy findings. A limitation of this post hoc analysis was the small sample size for patients with conjunctival infections due to any one of these pathogens even when pooled across four clinical studies. A statistical evaluation of outcomes among besifloxacin-treated patients compared with vehicle-treated patients was only practical for the largest of the pooled data sets - that of infections caused by methicillin-resistant staphylococci - and showed significantly higher rates for bacterial eradication with besifloxacin treatment compared to vehicle treatment. Nevertheless, the available clinical data, in conjunction with in vitro MIC data, are supportive of the efficacy of besifloxacin ophthalmic suspension $0.6 \%$ against these infections of concern.

\section{Acknowledgments}

This post hoc analysis was conducted by Bausch + Lomb, which designed and conducted the original studies. Editorial assistance was provided by Churchill Communications, Maplewood, NJ, USA, and was funded by Bausch + Lomb. The study data were presented in part at the 2012 annual meeting of the Association for Research in Vision and Ophthalmology, May 6-10, 2012, Fort Lauderdale, FL, USA; the 28th congress of the Asia-Pacific Academy of Ophthalmology, January 17-20, 2013, Hyderabad, India; and the 2013 annual meeting of the American Academy of Optometry, October 22-26, 2013, Seattle, WA, USA.

\section{Disclosure}

TLC, TWM, and HHD are employees of Bausch + Lomb, while LSG was an employee of Bausch + Lomb at the time of the study conduct. The authors report no other conflicts of interest in this work. All authors take responsibility for the integrity of the data and accuracy of the data analysis.

\section{References}

1. Tarabishy AB, Jeng BH. Bacterial conjunctivitis: a review for internists Cleve Clin J Med. 2008;75(7):507-512.

2. Golde KT, Gardiner MF. Bacterial conjunctivitis in children: a current review of pathogens and treatment. Int Ophthalmol Clin. 2011;51:85-92.

3. Høvding G. Acute bacterial conjunctivitis. Acta Ophthalmol. 2008;86(1) 5-17.

4. Pichichero MP. Bacterial conjunctivitis in children: antibacterial treatment options in an era of increasing drug resistance. Clin Pediatr (Phila). 2011;50(1):7-13 
5. Alvarenga LS, Ginsberg B, Mannis MJ. Bacterial conjunctivitis. In: Tasman W, Jaeger EA, editors. Duane's Ophthalmology [online]. 12th ed. Philadelphia, PA: Lippincott Williams and Wilkins; 2013.

6. Haas W, Gearinger LS, Usner DW, DeCory HH, Morris TW. Integrated analysis of three bacterial conjunctivitis trials of besifloxacin ophthalmic suspension, $0.6 \%$ : etiology of bacterial conjunctivitis and antibacterial susceptibility profile. Clin Ophthalmol. 2011;5:1369-1379.

7. Sheikh A, Hurwitz B, van Schayck CP, McLean S, Nurmatov U. Antibiotics versus placebo for acute bacterial conjunctivitis. Cochrane Database Syst Rev. 2012;(9):CD001211.

8. Abelson M, Protzko E, Shapiro A, Garces-Soldana A, Bowman L. A randomized trial assessing the clinical efficacy and microbial eradication of $1 \%$ azithromycin ophthalmic solution vs tobramycin in adult and pediatric subjects with bacterial conjunctivitis. Clin Ophthalmol. 2007;1(2):177-182.

9. Hautala N, Koskela M, Hautala T. Major age group-specific differences in conjunctival bacteria and evolution of antimicrobial resistance revealed by laboratory data surveillance. Cur Eye Res. 2008;33: 907-911.

10. Feder RS, Dunn SP, Jones MR, et al. American Academy of Ophthalmology Cornea/External Disease Panel. Preferred Practice Pattern ${ }^{\circledR}$ Guidelines. Conjunctivitis - Limited Revision. San Francisco, CA: American Academy of Ophthalmology; 2011. Available from: http://one. aao.org/preferred-practice-pattern/conjunctivitis-ppp--2013. Accessed May 7, 2013.

11. American Academy of Ophthalmology Cornea/External Disease Panel. Preferred Practice Pattern ${ }^{\circledR}$ Guidelines. Bacterial Keratitis. San Francisco, CA: American Academy of Ophthalmology; 2011. Available from: http://one.aao.org/preferred-practice-pattern/bacterial-keratitisppp--2013. Accessed May 7, 2013.

12. Barquet N, Gasser I, Domingo P, Moraga FA, Macaya A, Elcuaz R. Primary meningococcal conjunctivitis: report of 21 patients and review. Rev Infect Dis. 1990;12(5):838-847.

13. Parment PA. The role of Serratia marcescens in soft contact lens associated ocular infections. Acta Ophthalmol Scand. 1997;75:67-71.

14. Equi RA, Green WR. Endogenous Serratia marcescens endophthalmitis with dark hypopyon: case report and review. Surv Ophthlamol. 2001;46: 256-268.

15. Irvine WD, Flynn HW Jr, Miller D, Pflugfelder SC. Endophthalmitis caused by gram-negative organisms. Arch Ophthalmol. 1992;110: $1450-1454$

16. Dutta D, Cole N, Willcox M. Factors influencing bacterial adhesion to contact lenses. Mol Vis. 2012;18:14-21.

17. Fleiszig SM. The Glenn A. Fry award lecture 2005. The pathogenesis of contact lens-related keratitis. Optom Vis Sci. 2006;83:866-873.

18. Willcox MD. Pseudomonas aeruginosa infection and inflammation during contact lens wear: a review. Optom Vis Sci. 2007;84:273-278.

19. Abbot RL, Halfpenny CP, Zegans M, Kremer PA. Bacterial corneal ulcers. In: Tasman W, Jaeger EA, editors. Duane's Ophthalmology [online]. 12th ed. Philadelphia, PA: Lippincott Williams and Wilkins; 2013.

20. Tipple C, Smith A, Bakowska E, Corbett MC. Corneal perforation requiring corneal grafting: a rare complication of gonococcal eye infection. Sex Transm Infect. 2010;86(6):447-448.

21. Kawashima M, Kawakita T, Den S, Tomita M, Shimazaki J. Surgical management of corneal perforation secondary to gonococcal keratoconjunctivitis. Eye (Lond). 2009;23(2):339-344.

22. Schwab L, Tizazu T. Destructive epidemic of Neisseria gonorrheae keratoconjunctivitis in African adults. Br J Ophthalmol. 1985;69(7): 525-528.

23. Antibiotic Resistance Threats in the United States, 2013. US Department of Health and Human Services Centers for Disease Control and Prevention; 2013. Available from: http://www.cdc.gov/drugresistance/ threat-report-2013. Accessed October 2, 2013.

24. Freidlin J, Acharya N, Lietman TM, Cevallos V, Whitcher JP, Margolis TP. Spectrum of eye disease caused by methicillin-resistant Staphylococcus aureus. Am J Ophthalmol. 2007;144:313-315.
25. Marangon FB, Miller D, Muallem MS, Romano AC, Alfonso EC. Ciprofloxacin and levofloxacin resistance among methicillin-sensitive Staphylococcus aureus isolates from keratitis and conjunctivitis. Am J Ophthalmol. 2004;137:453-458.

26. Sharma S. Antibiotic resistance in ocular bacterial pathogens. Ind $J$ Med Microbiol. 2011;29(3):218-222.

27. Asbell PA, Colby KA, Deng S, et al. Ocular TRUST: nationwide antimicrobial susceptibility patterns in ocular isolates. Am JOphthalmol. 2008;145:951-958.

28. Adebayo A, Parikh JG, McCormick SA, et al. Shifting trends in in vitro antibiotic susceptibilities for common bacterial conjunctival isolates in the last decade at the New York Eye and Ear Infirmary. Graefes Arch Clin Exp Ophthalmol. 2011;249(1):111-119.

29. Cavuoto K, Zutshi D, Karp CL, Miller D, Feuer W. Update on bacterial conjunctivis in South Florida. Ophthalmology. 2008;115(1): $51-56$.

30. Elsahn AF, Yildiz EH, Jungkind DL, et al. In vitro susceptibility patterns of methicillin-resistant Staphylococcus aureus and coagulasenegative Staphylococcus corneal isolates to antibiotics. Cornea. 2010;29:1131-1135.

31. Haas W, Pillar CM, Torres M, Morris TW, Sahm DF. Monitoring antibiotic resistance in ocular microorganisms: results from the Antibiotic Resistance Monitoring in Ocular micRorganisms (ARMOR) 2009 surveillance study. Am J Ophthalmol. 2011;152(4):567-574.

32. Haas W, Pillar CM, Zurenko GE, Lee JC, Brunner LS, Morris TW. Besifloxacin, a novel fluoroquinolone, has broad-spectrum in vitro activity against aerobic and anaerobic bacteria. Antimicrob Agents Chemother. 2009;53(8):3552-3560.

33. McDonald M, Blondeau JM. Emerging antibiotic resistance in ocular infections and the role of fluoroquinolones. J Cataract Refract Surg. 2010;36(9):1588-1598.

34. Rutar T, Chambers HF, Crawford JB, et al. Ophthalmic manifestations of infections caused by USA300 clone of community-associated methicillin-resistant Staphylococcus aureus. Ophthalmology. 2006;113: $1455-1462$.

35. Rutar T, Zwick OM, Cockerham KP, Horton JC. Bilateral blindness from orbital cellulitis caused by community-acquired methicillinresistant Staphylococcus aureus. Am J Ophthalmol. 2005;140: 740-742.

36. Sotozono C, Ingaki K, Fujita A, et al. Methicillin-resistant Staphylococcus aureus and methicillin-resistant Staphylococcus epidermidis infections in the cornea. Cornea. 2002;21(Supp1 7):S94-S101.

37. Smith A, Pennefather PM, Kaye SB, Hart CA. Fluoroquinolones: place in ocular therapy. Drugs. 2001;61(6):747-761.

38. Mah FS. Fourth-generation fluoroquinolones: new topical agents in the war on ocular bacterial infections. Curr Opin Ophthalmol. 2004; $15: 316-320$

39. Besivance ${ }^{\mathrm{TM}}$ (besifloxacin ophthalmic suspension 0.6\%) [package insert]. Rochester, NY: Bausch and Lomb Incorporated; 2012.

40. Cambau E, Matrat S, Pan XS, et al. Target specificity of the fluoroquinolone besifloxacin in Streptococcus pneumoniae, Staphylococcus aureus and Escherichia coli. J Antimicrob Chemother. 2009;63(3): 443-450.

41. Haas W, Gearinger LS, Hesje CK, Sanfilippo CM, Morris TW. Microbiological etiology and susceptibility of bacterial conjunctivitis isolates from clinical trials with ophthalmic, twice-daily besifloxacin. Adv Ther. 2012;29(5):442-455.

42. Miller D, Chang JS, Flynn HW, Alfonso EC. Comparative in vitro susceptibility of besifloxacin and seven comparators against ciprofloxacin- and methicillin-susceptible/nonsusceptible staphylococci. J Ocul Pharmacol Ther. 2013;29(3):339-344.

43. Friedlaender MH, Protzko E. Clinical development of $1 \%$ azithromycin in DuraSite, a topical azalide anti-infective for ocular surface therapy. Clin Ophthalmol. 2007;1(1):3-10.

44. Bowman LM, Si E, Pang J, Archibald R, Friedlaender M. Development of a topical polymeric mucoadhesive ocular delivery system for azithromycin. J Ocul Pharmacol Ther. 2009;25(2):133-139. 
45. Si EC, Bowman LM, Hosseini K. Pharmacokinetic comparisons of bromfenac in DuraSite and Xibrom. $J$ Ocular Pharmacol Ther. 2011;27(1):61-66.

46. Akpek EK, Vittitow J, Verhoeven RS, et al. Ocular distribution and pharmacokinetics of a novel ophthalmic $1 \%$ azithromycin formulation. J Ocul Pharmacol Ther. 2009;25(5):433-439.

47. Wu EC, Kowalski RP, Romanowski EG, Mah FS, GordonYS, Shanks RM AzaSite ${ }^{\circledR}$ inhibits Staphylococcus aureus and coagulase-negative Staphylococcus biofilm formation in vitro. J Ocul Pharmacol Ther. 2010;26(6):557-562.

48. Silverstein BE, Morris TW, Gearinger LS, Decory HH, Comstock TL. Besifloxacin ophthalmic suspension $0.6 \%$ in the treatment of bacterial conjunctivitis patients with Pseudomonas aeruginosa infections. Clin Ophthalmol. 2012;6:1987-1996.

49. Bausch and Lomb Incorporated. Clinical and Microbial Efficacy of ISV403 in Bacterial Conjunctivitis. Available from: http://clinicaltrials. gov/show/NCT00622908. NLM identifier: NCT00622908. Accessed February 18, 2014.

50. Bausch and Lomb Incorporated. A Study to Determine if $0.6 \%$ ISV403 is Safe and Effective in the Treatment of Bacterial Conjunctivitis. Available from: http://clinicaltrials.gov/show/NCT00347932. NLM identifier: NCT00347932. Accessed February 18, 2014.

51. Bausch and Lomb Incorporated. Efficacy of Besifloxacin Ophthalmic Suspension in the Treatment of Bacterial Conjunctivitis. Available from: http://clinicaltrials.gov/show/NCT00972777. NLM identifier: NCT00972777. Accessed February 18, 2014.

52. Bausch and Lomb Incorporated. A Study to Investigate the Safety and Efficacy of BOL-303224 in the Treatment of Bacterial Conjunctivitis. Available from: http://clinicaltrials.gov/show/NCT00348348. NLM identifier: NCT00348348. Accessed February 18, 2014.

53. Tepedino ME, Heller WH, Usner DW, et al. Phase III efficacy and safety study of besifloxacin ophthalmic suspension $0.6 \%$ in the treatment of bacterial conjunctivitis. Curr Med Res Opin. 2009;25(5): 1159-1169.

54. Karpecki P, Depaolis M, Hunter JA, et al. Besifloxacin ophthalmic suspension $0.6 \%$ in patients with bacterial conjunctivitis: a multicenter, prospective, randomized, double-masked, vehicle-controlled, 5-day efficacy and safety study. Clin Ther. 2009;31(3):514-526.

55. McDonald MB, Protzko EE, Brunner LS, et al. Efficacy and safety of besifloxacin ophthalmic suspension $0.6 \%$ compared with moxifloxacin ophthalmic solution $0.5 \%$ for treating bacterial conjunctivitis. Ophthalmology. 2009;116(9):1615-1623.

56. DeLeon J, Silverstein BE, Allaire C, et al. Besifloxacin ophthalmic suspension $0.6 \%$ administered twice daily for 3 days in the treatment of bacterial conjunctivitis in adults and children. Clin Drug Investig. 2012;32(5):303-317.

57. Cagle GD, Abshire RL. Quantitative ocular bacteriology: a method for the enumeration and identification of bacteria from the skin-lash margin and conjunctiva. Invest Ophthalmol Vis Sci. 1981;20(6):751-757.

58. Leibowitz HM. Antibacterial effectiveness of ciprofloxacin $0.3 \%$ ophthalmic solution in the treatment of bacterial conjunctivitis. Am J Ophthalmol. 1991;112(Suppl 4):29S-333S.

59. Methods for Dilution Antimicrobial Susceptibility Tests for Bacteria That Grow Aerobically; Approved Standard-Sixth Edition. CLSI document M07-A6. Wayne, PA: Clinical and Laboratory Standards Institute; 2003.

\section{Clinical Optometry}

\section{Publish your work in this journal}

Clinical Optometry is an international, peer-reviewed, open access journal publishing original research, basic science, clinical and epidemiological studies, reviews and evaluations on clinical optometry. All aspects of patient care are addressed within the journal as well as the practice of optometry including economic and business analyses. Basic and clinical
60. Methods for Dilution Antimicrobial Susceptibility Tests for Bacteria That Grow Aerobically; Approved Standard-Eighth Edition. CLSI document M07-A8. Wayne, PA: Clinical and Laboratory Standards Institute; 2009

61. Performance Standards for Antimicrobial Susceptibility Testing: Fourteenth Informational Supplement. CLSI document M100-S14. Wayne, PA: Clinical and Laboratory Standards Institute; 2004.

62. Performance Standards for Antimicrobial Susceptibility Testing; Sixteenth Informational Supplement. CLSI document M100-S16. Wayne, PA: Clinical and Laboratory Standards Institute; 2006.

63. Performance Standards for Antimicrobial Susceptibility Testing: Nineteenth Informational Supplement. CLSI document M100-S19. Wayne, PA: Clinical and Laboratory Standards Institute; 2009.

64. Besivance ${ }^{\mathrm{TM}}$ (besifloxacin ophthalmic suspension 0.6\%) [package insert]. Rochester, NY: Bausch and Lomb Incorporated; 2009.

65. Proksch JW, Granvil CP, Siou-Mermet R, Comstock TL, Paterno MR, Ward KW. Ocular pharmacokinetics of besifloxacin following topical administration to rabbits, monkeys, and humans. J Ocul Pharmacol Ther. 2009;25(4):335-344.

66. Michaud L. Efficacy of besifloxacin in the treatment of corneal ulcer. Clinical and Refractive Optometry. 2011;22(5/6):90-93.

67. Turaka K, Penne RB, Rapuano CJ, et al. Giant fornix syndrome: a case series. Ophthal Plast Reconstr Surg. 2012;28(1):4-6.

68. Sanders ME, Moore QC 3rd, Norcross EW, et al. Comparison of besifloxacin, gatifloxacin, and moxifloxacin against strains of Pseudomonas aeruginosa with different quinolone susceptibility patterns in a rabbit model of keratitis. Cornea. 2011;30(1):83-90.

69. Sanders ME, Moore QC 3rd, Norcross EW, Shafiee A, Marquart ME. Efficacy of besifloxacin in an early treatment model of methicillinresistant Staphylococcus aureus keratitis. J Ocul Pharmacol Ther. 2010;26(2):193-198.

70. Sanders ME, Norcross EW, Moore QC 3rd, Shafiee A, Marquart ME. Efficacy of besifloxacin in a rabbit model of methicillin-resistant Staphylococcus aureus keratitis. Cornea. 2009;28(9):1055-1060.

71. Hwang DG, Schanzlin DJ, Rotberg MH, Foulks G, Raizman MB; Levofloxacin Bacterial Conjunctivitis Placebo-controlled Study Group. A phase III, placebo controlled clinical trial of $0.5 \%$ levofloxacin ophthalmic solution for the treatment of bacterial conjunctivitis. Br J Ophthalmol. 2003;87:1004-1009.

72. Power WJ, Collum LM, Easty DL, et al. Evaluation of efficacy and safety of ciprofloxacin ophthalmic solution versus chloramphenicol. Eur J Ophthalmol. 1993;3(2):77-82.

73. DeCory HH, Morris TW, Comstock TL. Clinical efficacy of besifloxacin ophthalmic suspension, $0.6 \%$ against MRSA and MRSE. Presented at: 2012 annual meeting of the Association for Research in Vision and Ophthalmology; May 6-10, 2012; Fort Lauderdale, FL.

74. Comstock TL, DeCory HH, Gearinger LS, Morris TW. Microbiological efficacy of besifloxacin ophthalmic suspension, $0.6 \%$ against bacterial conjunctivitis pathogens of ophthalmic concern. Presented at: 28th congress of the Asia-Pacific Academy of Ophthalmology; January 17-20, 2013; Hyderabad, India. research papers are published that cover all aspects of optics, refraction and its application to the theory and practice of optometry. The manuscript management system is completely online and includes a very quick and fair peer-review system, which is all easy to use. Visit http://www.dovepress. com/testimonials.php to read real quotes from published authors. 